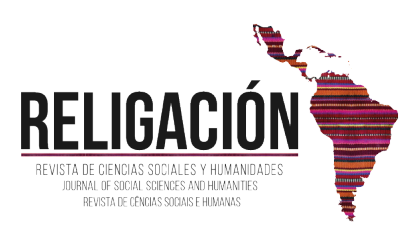

Dossier

\title{
El papel del trabajo en la hominizacion y humanización
}

\author{
The role of work in the hominization and humanization
}

\begin{abstract}
Miguel Ángel Adame Cerón | Escuela Nacional de Antropología e Historia - MÉXXCO |
Profesor-Investigador de Tiempo Completo adscrito a la Licenciatura en Antropología Social de la Escuela Nacional de Antropología e Historia. E-mail: adameguel@ yahoo.com.mx
\end{abstract}

RESUMEN: El presente texto lleva a cabo un rescate y una actualización del célebre ensayo de F. Engels: "El papel del trabajo en la transformación del mono en hombre". Se destaca su importancia como una obra que forma parte de los trabajos del materialismo dialéctico e histórico que él y K. Marx escribieron a lo largo de su vida, y en la cual se delinea una secuencia de componentes decisivos de corte metabólico (autotransformador y ecológico) en la formación de la especie humana y en vistas de su desarrollo pleno, el proceso de trabajo como actividad orgánica, técnica y consciente es la clave en la praxis socio-cultural e histórica humana del pasado, del presente y del porvenir. Se realiza también la actualización, conforme a datos e informaciones de las ciencias paleoantropológicas, de la argumentación de Engels respecto a lo que actualmente se llama proceso de hominización y sapientización, llegando a la conclusión de la vigencia de sus aportes.

Palabras claves: Proceso de trabajo, proceso de hominización, proceso de sapientización, materialismo histórico y dialéctico, ecología.

\begin{abstract}
This paper carries out a rescue and an update of the famous essay by Engels "El papel del trabajo en la transformación del mono en hombre". Its importance is highlighted as a work that is part of the works of dialectical and historical materialism that he and K. Marx wrote throughout their lives, and in which a sequence of decisive components of a metabolic nature is outlined (autotransformer and ecological) in the formation of the human species and in view of its full development, the work process as organic, technical and conscious activity is the key in the sociocultural and human historical praxis of the past, the present and the future. Updating, according to data and information from the paleoanthropological sciences, of Engels' argumentation regarding what is currently called the process of hominization and sapientization, is also carried out, concluding the validity of his contributions.
\end{abstract}

Keywords: Work process, hominization process, sapientization process, historical and dialectical materialism, ecology. 


\title{
INTRODUCCIÓN
}

\begin{abstract}
El hombre occidental tiende a pensar que puede doblegar la naturaleza. Hemos aprendido a subyugarla, pero estamos ciegos. Necesitamos una ciencia de la sabiduría.
\end{abstract}

Frank Herbert

La mayoría de los comentaristas de este texto clásico de Engels, sólo se han dedicado a reseñar y comentar la primera parte del mismo y básicamente los aspectos referidos a lo que se conoce actualmente como proceso de hominización (la transformación del simio en homo, es decir la formación del género homo, Klamroth, 1985) y proceso de sapientización (la trasformación del homo en homo sapiens, Morin, 1980) no van más allá; quizá porque no se han percatado de sus alcances mayores, o no les ha interesado ir más allá, o hacen una lectura inmediatista -no lo suficientemente profunda- de este sucinto texto. Por ejemplo, Martínez refiere que: "Hacia 1876 Federico Engels escribió un pequeño ensayo en que proponía la vinculación entre el trabajo en general y el proceso de hominización como se le denomina ahora" (2019: 73).

Por nuestra parte avanzamos planteando lo siguiente: que "El papel del trabajo en la transformación del mono en hombre" no es un escrito pensado de antemano con este título por el autor, sino que era parte de una Introducción a un trabajo más extenso denominado Tres formas fundamentales de esclavización. Obra ésta que no realizó y que, al quedarse sólo con el manuscrito inicial, lo denominó de esa manera porque la explicación del trabajo humano en sus orígenes era el fundamento temático del conjunto de su argumentación. Ésta sería, pues, más completa, pero vemos que en "El papel del trabajo..." sólo se esboza en sus puntos nodales el tema mayor, concretamente el referido a las "esclavitudes", que serían las experimentadas en la historia respecto: a) a las imposiciones de la naturaleza al ser humano, b) luego las del ser humano sobre el ser humano y c) finalmente las del ser humano sobre la naturaleza; en la cuales la dialéctica del metabolismo naturaleza-humano-naturaleza no ha sido armonizado por la (s) sociedad (es) humana (s). Así, Engels argumenta que en la historia humana escasa o "prehistoria humana", ellas se han desenvuelto como contrasentidos, pero que 1) con el desarrollo de la ciencia-técnica humana en el capitalismo (apropiada y dominada por el capital) manifestada en el trabajo automatizado, y 2) con el desarrollo de la organización y la conciencia de los trabajadores, en dicho régimen capitalista se posibilita un proceso de verdadera liberación (con la revolución comunista) de dichas esclavizaciones.

Así pues, en dicha frustrada Introducción a "Tres formas fundamentales de esclavización" se pueden distinguir tres temas enlazados: (A) una reconstrucción lógico-histórica hipotética de la secuencia del proceso de hominización-sapientización construida sobre la metodología de la dialéctica de la naturaleza y la dialéctica social; pero no sólo, sino que también: (B) una crítica histórica al sistema capitalista y su ciencia de la economía política y derivadas $^{1}$ y en general una crítica a todos los regímenes socioeconómicos y político-culturales precapitalistas limitados o escasos, creados por las sociedades humanas a lo largo de la historia; e igualmente: (C) una propuesta de lograr un proceso de humanización plena con base en una concepción materialista crítica de la historia de la humanidad que -ahora podríamos subrayar- contiene claramente una perspectiva ecológica de búsqueda y realización de un metabolismo armónico con la naturaleza. Todo este contenido y su desarrollo esbozado en este escrito engelsiano, están sustentados en el comunismo revolucionario pro realizador del ser humano pleno; valiéndose para ello, pues, de dicho materialismo histórico-dialéctico ecológico construido durante años por su amigo y camarada Karl Marx y él mismo.

Friedrich Engels va a retomar y desplegar dicha perspectiva en este trabajo y en otros asociados a él, usando como base, como él mismo lo destaca, escritos pasados de juventud que él mismo y Marx escribieron; concretamente los recupera en dos obras que igualmente tratan el asunto del «desarrollo histórico de la humanidad». Nos referimos a los textos: El Origen de la Familia, la propiedad privada y el Estado de 1884 y Ludwing Feuerbach y el fin de la filosofía clásica alemana (1886).

Subrayamos, entonces, que el quid del escrito que nos compete, y que coincide en cierta medida con aquellos dos, es la centralidad de la praxis, de los actos y de las acciones humanas, cuyo corazón transversal, en este caso es el papel del trabajo o, mejor, la dialéctica o movimiento del trabajo humano visto, como dice K. Marx en los Grundrisse como movimiento de la producción social o de la sociedad como un todo (p. 237). En efecto se trata, pues, del movimiento procesual o proceso constante adecuado a fines como parte nodal de lo que Karl Marx planteó (Elementos fundamentales, cuaderno el Proceso de Trabajo, y El Capital, Tomo I, capítulo trece, nota 4) como la creación de los órganos inmediatos de la práctica social del proceso vital, órganos sociales de la producción de la vida humana u órganos de la voluntad humana en su actuación sobre la naturaleza. Esta perspectiva orgánica los lleva a Marx (y Engels) a formular la necesidad de tener una mirada crítica de la tecnología y su historia. Puesto que dichos órganos culminarán históricamente en la gran industria capitalista convertidos tecnocientíficamente -ya no en aquellos iniciales instrumentos y herramientas relativamente sencillas y toscas del proceso de hominización

1 Véase el temprano ensayo de Engels de 1844: "Esbozo de la crítica de la economía política". 
en las industrias líticas- sino en poderosas máquinas (que cada vez en mayor medida van a producir medios de producción) conformándose en esta era capitalista en el «Social General Intellect»; en el cual está presente el saber histórico acumulado de la sociedad, concretamente en su forma de conocimiento científico de las ciencias y técnicas experimentales (físicas y sociales), pero apropiadas y manipuladas por el capital.

Dicha dialéctica del trabajo y de sus órganos y medios de producción, específicamente de sus instrumentos y herramientas de trabajo, que va crecientemente en su desarrollo histórico abriendo necesidades y capacidades nuevas y relativamente progresivas, desde la hominización y en la humanización y que potencialmente culminarían en la revolución y la sociedad comunista.

F. Engels pone el acento en este escrito en que las acciones (como en todos los demás animales e incluso seres vivos que reaccionan) tienen consecuencias o repercusiones en la dialéctica natural (como en todos los seres vivos), pero destacadamente como praxis del homo sapiens se extienden y complejizan ahora como parte de una dialéctica social y cultural. Esa es su peculiaridad histórica dado que, a la praxis humana en pleno capitalismo, se le presenta como gran desafío el resolver las contradicciones y las consecuencias negativas que traen las praxis natural-sociales humanas históricamente desplegadas, en lo que Marx llamó «la prehistoria humana»; es decir acciones todavía no plenamente dominadas o controladas como especie sui generis: sapiens, consciente y libre.

Para Engels, entonces, de lo que se trata con ello es de aprender y comprender las lecciones y errores antiecológicos y antisociales de esas praxis humanas inconscientes, poco conscientes, no planeadas/previstas suficientemente (es decir inmediatistas). Su finalidad -en buena parte ecológica-, será ejercer el trabajo, la técnica, la producción y, en general, todos los actos humanos conforme a su naturaleza no animalesca, conforme a las cualidades humanas formadas desarrolladas en el surgimiento del género homo y propiamente en la especie sapiens sapiens. Ello para no seguir cayendo en sin sentidos, efectos contraproducentes, despropósitos y contrafines, sino superarlos dialécticamente en la emancipación y realización de la vida humana futura.

Este ensayo lo vamos a dividir en dos partes. La primera para desglosar y comentar propiamente el conjunto del texto de Engels. Y la segunda para ilustrar y actualizar los componentes específicos nodales que tienen que ver concretamente con el proceso de hominización que Engels esbozó de manera magistral y que han servido para fundamentar lógica e históricamente la centralidad del proceso de trabajo en el surgimiento del género homo y peculiarmente del homo sapiens sapiens como especie bio-socio-cultural cósmica (Morin, dixit).

\section{EL TEXTO DEL "PAPEL DEL TRABAJO EN LA TRANSFORMACIÓN DEL MONO EN HUMANO" VISTO EN SU TOTALIDAD}

Veamos su argumentación, primero en las premisas, luego en los antecedentes darwinianos y finalmente de manera más amplia y secuencial en 8 pasos decisivos, como él los denomina:

0. Premisas. En primer lugar, para Friedrich Engels está la unidad de las dos fuentes o dos "progenitores" de la riqueza humana: la (madre) naturaleza y el (padre) trabajo. Cita a los especialistas de la economía política². Para Engels, la naturaleza es la proveedora de los materiales que el trabajo humano convierte en riqueza y el trabajo humano es "la condición básica y fundamental de toda la vida humana" a tal grado que, dice, "hasta cierto punto, debemos decir que el trabajo ha creado al propio humano". Con esta frase nos indica que va a ilustrar la importancia activa o mayormente activa del trabajo en la conformación de toda la historia humana. Diríamos actualmente que en tres grandes pautas o secuencias históricas: 1) en la hominización (transformación del simio en homo, pasando por los homínidos), 2) en la sapientización (transformación del homo en homo sapiens y 3) en la humanización, es decir, en la verdadera o (proto) plena humanidad (transformación del homo sapiens en plenamente humano). En segundo lugar, están los antecedentes en la ciencia de la evolución. Aquí señala que Charles Darwin (The descent of Man: 1871) dio una descripción aproximada de una raza de monos antropomorfos extraordinariamente desarrollada que vivió en algún lugar de la zona tropical y vivían en los árboles y formaban manadas ${ }^{3}$.

1. Inicio de los pasos decisivos. Este mono al caminar por el suelo "se fue acostumbrando a prescindir de las manos" y entonces empezaron a adoptar más y más una posición erecta. Este es el primer paso decisivo de 7 reales y uno potencial (un total de ocho) de la historia de la transformación del simio en humano y potencialmente en plenamente humano. Por tanto, para Engels, ese fue el inicio para el tránsito del mono al humano (decimos ahora con más precisión del simio en homínido y de homínido en género humano hasta culminar en la especie homo sapiens sapiens). Para aquellos monos primero fue una norma y luego una necesidad por lo que en aquel entonces las manos tenían que ejecutar funciones cada vez más variadas, desarrollándose la «división de funciones» entre las extremidades, entre pies y manos. Así Engels enumera las tareas más numerosas de las manos: tales como, recoger y sostener

2 Marx cita, en este mismo sentido, en El Capital, a William Petty 1623-1687): "El trabajo es el padre y principio activo de la riqueza y las tierras son la madre"

3 En efecto, Ch. Darwin en dicha obra señala textualmente lo siguiente: "Todo pues, prueba la estrecha y muy íntima relación que existe entre el hombre y los animales superiores, especialmente con los monos, así en lo que se refiere a la estructura general, como en los más pequeños de los tejidos y en su constitución y en su composición química (1985: 5). Igualmente, Darwin cita a Bischoff (1868) cuando este argumenta que: "El hombre se halla sobrado más cerca de los monos antropomorfos, a causa de los caracteres anatómicos de su cerebro..." (ibídem, p. 3). 
alimentos, construir nidos y tejadillos en los árboles, agarrar garrotes, aventar frutos y piedras y realizar operaciones sencillas semejantes a las que realizan los monos. Sin embargo, dice Engels, la mano primitiva de cualquier mono es incapaz de ejecutar los centenares de operaciones que realiza la mano humana como tal "perfeccionada por el trabajo durante centenares de miles de años". Y ejemplifica: "Ni una sola mano simiesca ha construido jamás un cuchillo de piedra por tosco que fuese". Traduciéndolo a los conocimientos actuales, los primates superiores antropomorfos (no homos) no desarrollaron jamás ninguna industria lítica o modo técnico. La explicación que proporciona Engels es que hubo un proceso evolutivo de operaciones sencillas a operaciones complejas y consistió en que "nuestros antepasados fueron adaptando poco a poco sus manos durante muchos miles de años de transición".

2. La mano se hizo libre sería el segundo paso decisivo, ya que pudo adquirir cada vez más: habilidad, destreza y flexibilidad que se "transmitía por herencia y se acrecía de generación en generación". Así la mano liberada y perfeccionada (anatómica y fisiológicamente) se convirtió en «el [primer] órgano del trabajo» y fue producto o resultado de éste mediante cada vez más aplicaciones a funciones nuevas y cada vez más complejas. Con ello lo que beneficiaba a la mano, beneficiaba a todo el cuerpo y organismo; en dos aspectos:

i) Interno: La marcha erguida sobre los pies y la mano cada vez más liberada-perfeccionada repercutieron por correlaciones de formas (Darwin dixit) sobre otras partes del organismo. Digamos que, ahora se sabe y en época de Engels no (como él mismo lo reconoce aquí), en la columna vertebral-cráneo-cerebro (foramen magnum), visión, pelvis-húmero, termorregulación-sudoración, acomodo de órganos, posición del pie y modo de caminar, etc.).

ii) Externo: repercusiones sociales de unos sujetos sobre otros y sobre el conjunto de la congregación, concretamente: ayuda mutua, actividad conjunta y reforzamiento de los lazos; progreso sobre el dominio sobre la naturaleza en el sentido de que el trabajo iba ampliando los horizontes haciéndole descubrir constantemente en los objetos nuevas propiedades hasta entonces desconocidas.

3. Tercer paso decisivo: la necesidad de mayor comunicación verbal (o como lo expresa Engels de "decirse algo" transmitiéndose información psicofectiva y relacional significativa y cada vez más precisa y puntual) de los unos a los otros. Es decir, modulaciones y articulaciones del sonido teniendo un papel central para nuestro autor la laringe (y demás organelos anatómicos del aparato fonador o vocal), respecto a esto nos señala la máxima lamarckiana: "la necesidad hizo al órgano"; es decir, que según Lamarck, los órganos se adquieren o se pierden como consecuencia del uso o desuso, y los caracteres adquiridos por un ser vivo son heredados por sus descendientes. La laringe y los órganos vocales formados dialécticamente en el caso ser humano resultaron ser apropiados para el lenguaje articulado y de esta manera la explicación dialéctica de su origen sólo es posible "a partir del proceso de trabajo y con el proceso de trabajo".

De esta forma la conexión del trabajo con el lenguaje influyó y estimuló el desarrollo del cerebro humano e igualmente "los instrumentos más inmediatos" de éste: los órganos de los sentidos (vista, olfato, oído y tacto). Con del desarrollo interactivo y mutuo de ambos se fue generando. a) mayor claridad de conciencia, b) mayor capacidad de abstracción y c) mayor grado de discernimiento; formando con ello una doble recursividad dialéctica de mutuas influencias: entre el trabajo y el lenguaje y entre el cerebro y los sentidos.

3. Este circuito dialéctico conforma un cuarto paso decisivo y es el que posibilita el primer avance de lo que Engels denomina la sociedad humana. que desde esta base se expresa en su desarrollo multidireccional y diverso en distintos pueblos con adelantos y retrocesos en esta procesualidad que hoy llamaríamos desarrollo sociocultural (y civilizacional).

5. A partir de aquí como quinto paso decisivo, los sapiens -a diferencia de los demás primates superiores que llevan a cabo una "explotación rapaz" e incluso despilfarradora de sus áreas de alimentos- haciendo uso de: a) su mayor inteligencia y b) su mayor capacidad de adaptación (hoy diríamos más precisamente de «adaptabilidad» ${ }^{4}$ ), en las diversas zonas de alimentación, ampliaron el rango de plantas comestibles; con lo que realizaron una alimentación cada vez más diversa y por tanto con mayor variedad de nuevas sustancias nutricionales, con lo que "creaban las condiciones químicas", fisiológicas y corporales para constituir una "dieta propiamente humana». Cuyas bases para Engels son las siguientes: 1) despliegue en la elaboración de instrumentos de trabajo (que a la vez fueron utilizados como armas) para hacerse de nuevos alimentos, 2) creación de instrumentos para la pesca y la caza con lo que se posibilitó: 3) el tránsito de la alimentación propiamente vegetal a la alimentación mixta (vegetal-animal), 4) el consumo de carne ofreció al organismo humano ingredientes esenciales para el mejor desempeño de las funciones de su organismo, especialmente en la potenciación funcional y el crecimiento de su cerebro (incluso el uso de la carne en la alimentación ha llevado en ciertas circunstancias a las prácticas del canibalismo), 5) igualmente trajo dos nuevos avances decisivos: el uso del fuego que redujo el proceso de digestión y la domesticación de animales que multiplicó la reserva de carne y de leche para obtenerlas de manera más regular, 6) el combinar la carne con la dieta vegetal (bases del omnivorismo) contribuyó poderosamente-dice Engels- a dar fuerza física y mental al humano al bridarle -en vías de consolidación- su "independencia" (respecto de la naturaleza).

6. El sexto paso decisivo fue su extensión geoclimática y ecológica, pues por su propia iniciativa -a diferencia

4 La adaptabilidad como capacidad de ajustarse transformando las condiciones medioambientales y sociales 
de los demás animales- se fue expandiendo y adaptando-transformando a los diferentes climas de los continentes y de los ecosistemas (latitudes, alturas, templados, fríos, etc.). Ello obligo a los seres humanos a realizar nuevas actividades y a generar nuevas necesidades de abrigo, vivienda, vestimenta, etc., creándose nuevas esferas cada vez más complejas, diversificadas y cada vez más perfeccionadas de trabajo material, cultural, semiótico, político y espiritual: ganadería, pesca, agricultura, alfarería, hilado, tejido, metales, navegación, comercio, artes y ciencias, posteriormente también el desarrollo de las naciones, el Estado y con ello el derecho, la política y la religión. Estas últimas, así como el origen de la explotación del propio trabajo y en general el rápido progreso de la civilización, son producto de la dinámica de las necesidades materiales "reflejadas naturalmente en la cabeza del ser humano que así cobra conciencia de ellas", y no -como creer la concepción idealista del mundo que ha dominado el pensamiento- exclusivamente al desarrollo y a la actividad cerebral.

Así pues, aquí Engels aprovecha para refrendar su propia concepción materialista dialéctico-histórica de los orígenes y de desarrollo/progreso del sapiens y de sus productos sociales, políticos y culturales materiales e institucionales con base en la dialéctica de la complejización de proceso de trabajo y el crecimiento y diversificación de las necesidades que fue llevando a los humanos a "plantearse y a alcanzar objetivos cada vez más elevados". Dicha concepción, dice, Engels, es diferente y crítica respecto del materialismo naturalista de la escuela darwiniana cuyos representantes en su época, eran aun incapaces de formarse una idea clara acerca de dichos orígenes y desarrollos, pues su "influencia idealista les impide ver el papel [histórico-genético] desempeñado por el proceso de trabajo".

El signo más distintivo o esencialmente diferente de los humanos respecto de los animales, observa Engels, se fundamenta en que: "Ni un solo acto planificado de ningún animal ha podido imprimir en la naturaleza «el sello de su voluntad». Solo el humano ha podido hacerlo". Esto es, que las acciones de los humanos sobre la naturaleza imprimen material y espiritualmente sus diversas y crecientes necesidades y fines y sus repercusiones sobre la misma son escalares: ecológicas, geológicas, energéticas y mentales. Por consiguiente, resume Engels, esa diferencia esencial radica en que los animales utilizan la naturaleza exterior y la modifican por el mero hecho de su presencia en ella. El humano, en cambio, transforma la naturaleza y la obliga así a servirle (servicio no utilitario), la domina (no utilitariamente) por efecto del proceso de trabajo. En este aspecto concuerda y complemente con lo planteado por Karl Marx en El Capital cuando éste dice en el capitulo V que:

El trabajo es, en primer lugar, un proceso entre el hombre y la naturaleza, un proceso que el hombre medio, regula y controla su metabolismo con la naturaleza. El hombre se enfrenta a la materia natural misma como un poder natural. Pone en movimiento las fuerzas naturales que pertenecen a su corporeidad, brazos y piernas, cabeza y manos, a fin de apoderarse de los materiales de la naturaleza bajo una forma útil para su propia vida. Al operar por medio de ese movimiento sobre la naturaleza exterior a él y transformarla, transforma a la vez su propia naturaleza.

Pero Engels plantea que dicho dominio si se toma como si se tratara de "victorias" sobre la naturaleza, bajo esa lupa, subraya con énfasis: "la madre naturaleza" toma su venganza del "padre trabajo". Ello porque -podríamos decir ahora- desde la perspectiva del ecologismo dialéctico crítico ${ }^{5}$, en las repercusiones o consecuencias imprevistas, o sea negativas, que se manifiestan -no necesariamente de manera inmediata sino en segunda o tercera instancia después de lo que se obtuvo con previsión o en primera instancia- "la naturaleza toma venganza". Por lo que dichos hechos, nos sigue diciendo Engels, nos recuerdan (a los humanos y específicamente a su trabajo productivo) que: "nuestro dominio sobre la naturaleza no se parece en nada al dominio de un conquistador sobre el pueblo conquistado". Pues abunda Engels que, siguiendo los elementos de humanismo naturalista o naturalismo humanista que Marx y él siguieron: «nosotros como humanos estamos en su seno y pertenecemos a la naturaleza». Y, por consiguiente: "todo nuestro dominio sobre ella consiste en que, a diferencia de los demás seres, somos capaces de conocer sus leyes y aplicarlas adecuadamente".

7. Y para F. Engels existe un gran avance científico en su época, que sería un séptimo paso decisivo crucial ya no sólo en la hominización-humanización, sino hacia la plena humanidad, principalmente de las Ciencias Naturales de la segunda mitad del siglo XIX, particularmente del conocimiento y comprensión de las leyes de la naturaleza (principalmente con el darwinismo y en general con la teoría evolucionista) y por ello se ha dado un importante paso para conocer tanto los efectos inmediatos como las consecuencias remotas de "nuestra intromisión en el curso natural de desarrollo". El meollo del asunto para Engels es que dichos avances científicos (o mejor, tecnocientíficos) posibilitan la prevención, el control cada vez mejor de las repercusiones no inmediatas a prever, y, por tanto, permiten controlar cada vez mejor las "remotas consecuencias naturales de nuestros actos en la producción". Y de esta manera, cuanto más sea esto una realidad, los hombres no sólo sentirán de nuevo y en creciente grado su unidad con la naturaleza (armonía con "la madre"), sino que la comprenderán más (comprendiendo así mismo su propia naturaleza construida también en el trabajo y con su trabajo), y, por ende: "más inconcebible será esa idea absurda y antinatural

5 Frank Herbert cuenta que leyó muchos libros para tratar de encontrar cuál es el meollo de la ecología y que se quedó con la definición de la ecología humana como la ciencia de entender «las consecuencias». En efecto, las consecuencias son un aspecto nodal de la praxis humana y específicamente del proceso de trabajo, pues éste se realiza como un intercambio metabólico del sujeto con y en la naturaleza, siendo el sujeto también naturaleza. K. Marx ya lo había dejado claro y Engels aquí lo recupera en clave ecologista. 
de la antítesis entre el espíritu y la materia, el hombre y la naturaleza y el alma y el cuerpo".

Pero el maestro Engels entonces, para dejar clara su perspectiva unitaria de superación de las antítesis, plantea que igualmente de lo que se trata es de prever no sólo las indirectas y remotas consecuencias del dominio y de la producción humana sobre la naturaleza exterior, sino también las repercusiones sociales de esas mismas acciones. Y para lograr cabalmente todo ello es fundamental: a) el conocimiento, control y dominio de las consecuencias directas e inmediatas a nivel natural y social la producción y b) el conocimiento, control y dominio de las consecuencias indirectas y remotas a nivel natural y social de la producción humana.

8. Se trataría, entonces de construir un octavo paso decisivo plenamente emancipador, pues nos enfatiza Engels: "hace falta una revolución que transforme por completo el modo de producción existente hasta hoy día" (el capitalismo) y, con él, el orden social productivista, inmediatista, antiecológico y antisocial vigente.

Resalta del viejo Engels, por tanto, que se trata de realizar una revolución que cree un nuevo orden natural-social productivo y en donde el proceso de trabajo tendrá un nuevo papel en la transformación del humano en verdadera y plenamente humano, un orden o modo de producción esencialmente diferente a todos los anteriores que tenga integrado realmente en su actuar social la planificación, prevención, y control de la producción (siendo una gran palanca de ayuda una ciencia-técnica crítica, liberada y emancipadora) siguiendo las leyes de la naturaleza y por ende que supere realmente sus utilitarismos y limitaciones de toda índole.

\title{
2. EL PROCESO DE HOMINIZACIÓN Y SAPIENTIZACIÓN VISTO HOY.
}

\begin{abstract}
El uso y la creación de medios de trabajo, aunque en germen se presentan en ciertas especies animales, caracterizan el proceso específicamente humano de trabajo, y de ahí que Franklin defina al hombre como a toolmaking animal, un animal que fabrica herramientas. La misma importancia que posee la estructura de los huesos fósiles para conocer la organización de especies animales extinguidas, la tienen los vestigios de medios de trabajo para formarse un juicio de formaciones económico-sociales perimidas. Lo diferencia una época de otras no es lo que se hace, sino cómo, con qué medios de trabajo se hace. Karl Marx
\end{abstract}

\section{Ampliación de la secuencia de los componentes de la hominización-sapientización.}

Faustino Cordón en un ensayo de $1982^{6}$, ha ampliado en ciertos aspectos evolutivos importantes el modelo o secuencia dialéctica propuesta por F. Engels respecto del proceso de hominización-sapientización. Vamos enseguida a recuperar su secuenciación ampliada incorporando informaciones y datos importantes de la paleoantropología de finales del siglo XX y principios del siglo XXI, sintetizados por Daniel Turbón (2006) y por otros paleoantropológos actuales, con el fin de ilustrar la solidez del desarrollo dialéctico en dicho proceso prehistórico expuesto por Engels en 1876.

La historia completa va en el rango de hace 25 millones de años (inicio del periodo geológico del «mioceno») a 200 mil aproximadamente (inicio de la aparición del sapiens sapiens). Se trata de explicar cómo una especie de mono se diferencia y da pie a la aparición de dos especies nuevas diferentes (especialización divergente). Lo que interesa es un proceso evolutivo millonario constitutivo de dos partes: en su primera parte, la transformación del mono en homínido y del medio del mono en medio del homínido y su perfeccionamiento recíproco; y, en su segunda parte, la transformación simultánea del homínido en humano y del medio animal del homínido en medio social del humano. En todo ese proceso se presenta las coevoluciones de: 1) el medio, 2) la conducta y 3) la configuración corporal del organismo.

Se inicia con un mono arborícola africano (posiblemente en la región de la actual Kenia) conocido domo "procónsul", es el mono ancestral común a las dos especies que se bifurcaron a partir de él. De este mono derivan tanto los póngidos como los homínidos, ambos de la superfamilia de los hominidae (hace 16-14 millones). Contaba con 4 manos para agarrarse a las ramas, se desplazaba sobre las ramas de los árboles de la fronda tropical; tenía extremidades inferiores más fuertes que las superiores, éstas últimas le servían para asir, coger alimentos, etc., su alimentación era predominantemente vegetaliana, sus caninos eran medianos y sus incisivos eran poco especializados.

La primera especie nueva derivada habitó el bosque denso y la segunda especie nueva habitó la periferia del bosque. Cada especie encontró una especialización ventajosa (sobre todo para buscar alimento) de la conducta emprendida por algunos individuos hábiles. 
La primera especie (especie ancestral de los póngidos) ejecutaba desplazamiento mediante la braquiación (colgándose y columpiándose), desarrollará más los brazos y el tórax y menos las piernas, los caracteres adquiridos se seleccionaron (por la presión de los animales de su medio) de los individuos que nacieron con las mejores aptitudes somáticas y conductuales (selección sostenida por miles de años). Dicha braquiación terminará modelando monos con tórax muy robustos y brazos muy fuertes de gran juego articular y con extremidades inferiores relativamente más débiles. También se redujo el pulgar de la mano y la disminución de su oponibilidad a otros dedos, con ello se redujo la capacidad de manipulación y obligó que la boca ayudara más a la mano para arrancar y limpiar la comida, con ello se dio cierto robustecimiento de los caracteres dentarios. Esta especie tuvo más ventaja en la parte más densa del bosque y allí eligió su territorio

La segunda especie divergida (ancestral de los homínidos) ejecutaba desplazamiento andando con cuatro manos, tenía cuerpo esbelto y con extremidades posteriores bien desarrolladas, conservando la plenitud funcional de la mano y dentición menos desarrollada. Realizaba exploración permanente de cada porción del bosque en grupos de individuos vinculados, coordinados y orientados en actividades de búsqueda de alimento, guiados por el oído y un surtido de gritos inarticulados, pero con tono indicador de la carga emotiva y de información de la conducta operante a seguir. Los demás sentidos para percibir el alimento, reconocer lo comestible y lo desechable conforme a la experiencia heredada de los padres y de la suya propia. Esta especie tuvo más ventaja y preferencia en la zona más discontinua y marginal del bosque donde existe la sabana (área mixta), se habituó a desplazarse atravesando el suelo y en éste tuvo que modificar su conducta.

Ambas especies (braqueadora y andadora) fueron gregarias y mayormente vegetalianas y progresaron su adaptación en sus respectivos hábitats, separándose y ocupando zonas contiguas.

La especie devenida en homínida tuvo que pasar mayor tiempo de estancia en el suelo por lo que tuvo que familiarizarse con él, observando y examinando en colectivo coordinadamente para poder atravesarlo (andarlo). Ante el mayor peligro e inseguridad de la sabana, se reforzó la cooperación, ayuda mutua y el gregarismo (y la organización del grupo).Y fue allí donde fue buscando y encontrando las mayores fuentes de su comida. Una vez allí este pro-homínido estaba ya disponible para el cambio en su forma corporal hacia la configuración erecta (postura erguida). Veamos la cita explicativa de esa crucial transformación por parte del biólogo F. Cordón:

\begin{abstract}
La necesidad de estar continuamente oteando todo el campo visual desde lo alto de su estatura [...] los obligada [a los miembros de esta especie] a desarrollar al máximo los músculos que se aplican a erguir el cuerpo y a mantener la cabeza alta [...] por el ejercicio [...], de unos caracteres adquiridos...Y fijando estas conquistas individuales e intransferibles a la descendencia, la selección natural [...]fue dejando para padres a los individuos con caracteres congénitos [...tales como]: estructura adecuada de la pelvis, de los huesos del pie; desplazamiento del foramen magnum del cráneo ${ }^{7}$, etc. (p. 68).
\end{abstract}

En efecto, el bipedismo o bipedalismo en el género homo tiene los siguientes caracteres evolutivos: La pelvis es más baja, ancha y redondeada que la de los otros primates y finalmente se constituye con forma «platipeloide», se da también rotación del ala ilíaca. Hay fortalecimiento de los glúteos mínimo y medio y las piernas son más largas y pesadas, existe una mayor anchura del sacro, mayor angulación de diáfisis del fémur sobre la horizontal de la articulación tibial. En el pie, el dedo gordo se hace paralelo respecto a los demás y se robustece notablemente; igualmente el talón se hace más largo y alto y actúa como trípode durante la marcha (Turbón, 2006).

Así, la postura erecta deja (mientras se anda o corre bípedamente o mediante el bipedalismo) potencialmente libres las manos para transportar continuamente un útil (palo, hueso, piedra, etc.), lo cual es una función ventajosa, incluso determinante o con valor de vida o muerte en determinadas situaciones (Cordón, 19:70). Dicha configuración en su función andadora bípeda y en su forma erguida se hizo costumbre unida a la tenencia y transporte del útil (instrumento). Así pues, esta conducta triplemente compuesta (postura erguida bipedalista y provista del útil fue la trascendente para la transición del mono en homínido y para la consolidación de esta especie ya divergida y específica como tal.

Las manos y todo el cuerpo entero se van adaptando a la tenencia, transporte y manejo del útil (herramienta). De aquí el útil progresa retroalimentativa y recíprocamente con el modo de usarlo (manipulación, manejo, control) y con la necesidad de reponerlo, reproducirlo-producirlo. Y aunque no lo dice con claridad Cordón, ello implica que se trata del proceso de trabajo para reponerlo-reproducirlo-producirlo, en el cual ambos progresan, se amplían y se perfeccionan: proceso de trabajo y manejo y uso del instrumento (de los instrumentos en vista a desarrollarlos como herramientas o kit herramental). Ello proporciona una gran ventaja en la competencia con otros animales y por ende ventaja en la lucha por la existencia y concretamente en la presión de la selección natural (en el medio) que va siendo

7 Es a través de este agujero u orificio occipital de forma oval que la médula espinal (contenida en la columna vertebral) y el cerebro están conectados, mediante arterias, nervios, etc., se encuentra situado en la parte posteroinferior del cráneo (base del cráneo, piso témporo occipital), a través del cual se establece la continuidad del sistema nervioso central hacia el raquis. 
disminuida paulatinamente para este homínido erecto y con proto herramienta, conforme dicha progresión y mutua retroalimentación perfeccionadora avanza hasta madurar en los primeros homos.

Faustino Cordón le dice de la siguiente manera:

El útil constituye un valioso auxiliar en la actividad mecánica del homínido y el perfeccionamiento del útil y del modo de aplicarlo, por lento que realmente fuese en esa época, era más rápido que el lentísimo progreso de la conducta general de otras especies superiores coetáneas [...] y, por ello, iría aumentando en densidad demográfica [...] y en conducta cooperante [...] cada vez más estrechamente [...] lo que en mayor o menor grado hubo de acelerar el progreso en el manejo de útiles [...] y las técnicas del manejo de ello (la de golpear con ellos, de lanzarlos, etc.) (pp. 72-73).

Existe, pues, una recursividad dialéctica entre el trabajo técnico de producir cada vez con más precisión-perfección el útil y la técnica de su aplicación-uso. Lo cual nos remite a señalar que es el papel del trabajo productivo con la liberación de las manos para manipular objetos y manejar el útil el que va cumpliendo su trascendental importancia, cabe por tanto señalar lo nodal que resulta el aprendizaje, enseñanza, transmisión de la habilidad para producir los útiles, como dice Engels para realizar las operaciones que implica la producción de estos primeros útiles elementales (y tener acceso a las materias para producirlos). La variedad de ellas y de sus consiguientes técnicas en la producción y uso de los útiles, implicándose y participando cada vez en mayor medida las partes y el cuerpo entero en ello.

De este modo, nos sigue indicando Cordón, con dichas conductas adquiridas se posibilitaron tanto el mejoramiento de la defensa, al usar los útiles como a circunstancias), como el tener mejor posición de acceso a una mayor gama de nuevos alimentos, al disputar con mejor éxito una cuota mayor de alimento desplazando de esta manera en alguna medida a los consumos especializados al que estaban habituados otras especies competitivas. Por consiguiente, su omnivorismo se comenzó a ampliar, su nutrición también mejoró de cierta manera y potenció con ello su crecimiento demográfico. El éxito también reforzó y complejizó la cooperación haciéndola variada y más íntima.

Con esto se fomentó la capacidad de emitir-distinguir-interpretar una gama de sonidos y gritos de comunicación cada vez más abundantes, diversos, con mayores articulados y significados.

Entonces aunando todos estos avances cabe voltear a ver la manera en que realizan ahora los desplazamientos por la sabana: a) erguidos en su postura corporal y su caminata, b) organizados de manera coordinada y cooperativa mirándose unos a otros y emitiendo gritos semiarticulados significativos, c) portando útiles como instrumentos de defensa y de búsqueda de comida que manejaban con habilidad, siendo su complemento y extensión somática. Uno de estos útiles fueron la transportación de teas o antorchas de fuego (previa producción, mantenimiento y control del mismo), fue esencial en el proceso evolutivo del homínido al humano: como materia, medio e instrumento de trabajo (curtir pieles, moldear útiles) como fuente de energía y calor (p.e en los primeros campamentos nocturnos como protección del frío y de otros animales). d) se expandieron a otros territorios previamente desconocidos, concretamente a zonas más frías.

Igualmente se crearon las condiciones para conseguir el autotrofismo vía el descubrimiento en la transformación del alimento ("modo de acción propio del humano") a través del medio principal: una nueva aplicación del fuego en el calor de la hoguera o fogón en el campamento para descansar-reposar (diurno y seminocturno) de la sabana. Y finalmente como potencializador y consolidador del lenguaje articulado, que tiene como función principal en ese periodo, la plasmación peculiar del pensamiento o experiencia comunicable. Así el lenguaje articulado propiamente humano es también un producto del desarrollo del proceso de trabajo pues se va forjando: "de una paciencia y de una capacidad de observación desarrollada por cientos de miles de años de elaboración de útiles; esto es de un homínido que poseía ya la autodosciplina que le permitía fijarse y alcanzar algunos objetivos o fines mediatos" (p. 87).

Entonces participa y complementa como instrumento u órgano cognoscitivo (donde participan el cerebro, el aparato fonador y la mente) en la posibilidad de nuevas operaciones realizables a nivel corporal: manos-cerebro-ojos-intelecto-aparato fonador.

Con la cocina del homo faber/hablante/cocinante se inició y marcó la ruta de toda la actividad artificial (superpuesta a la mecánica) de activar reacciones a nivel molecular en la transformación-preparación de alimentos cocinados: "desde la cocina, pasando por la cerámica, la metalurgia, los curtidos, la alquimia, etc., hasta llegar a la química moderna; habría que reconstruir el objeto de toda la actividad artesanal y luego industrial del hombre; hasta que ya en el siglo XIX, logró incidir en otros niveles (el electromagnetismo, la energía nuclear, etc.)", p. 91.

Así el ser humano se autoforma o autocrea como heterótrofo porque obtiene para su propia actividad un alimento nuevo (que no estaba biológicamente "destinado"). Con tres repercusiones importantes en su formación homo:

1) No se limita a buscar alimento y consumirlo, sino que: lo obtiene, lo produce, lo prepara y lo consumo cooperando y para provecho comunitario: "La progresiva capacidad de producir más alimento, iniciada por el ho- 
mínido ha multiplicado por 20,000 la población de sus descendientes (desde 100 a 200,000 homínidos a los 4 mil millones en aproximadamente 100 mil años)", p. 95.

2) De igual forma: "...los homínidos cocinantes se emanciparon de la presión selectiva de otros animales y en tanto, se constituyen unos a otros en medio exclusivo. Así pues, al cocinar los homínidos saltaron del medio animal al medio [propiamente] social [cultural], propio del hombre", pp. 99-100.

3) Con ello también consiguieron una forma importante de libertad, ya que en la culinaria en cada momento pueden a voluntad solicitar la colaboración de los otros, comunicándole algo en su presencia y en la acción que conviene realizar: cocinar les proporcionó una conciencia de agente, es decir, una capacidad de diferenciar ellos mismos de sus obras; y así a nivel del lenguaje les permitió relacionar con las primeras oraciones, voces sustantivas y voces verbales.

EL lenguaje articulado emergido desde entonces ha permitido al ser humano someter a experiencia comunicable (enunciar y comprender), aspectos cada vez más numerosos y complejos del proceso coherente de las palabras en acción, del pensamiento y desarrollo respecto de toda la naturaleza, pues dicho lenguaje es una capacidad de desarrollo transformador de la misma. Y por lo tanto se perfiló como una dimensión humana central en el dominio de ella como un todo.

De todo este complejo y dialéctico proceso de transformación de los homínidos en homos y de estos en sapiens, se produjeron (autoprodujeron) seres transmutados metamorfoseados con nuevas cualidades y nuevas acciones a desplegar en la historia humana.

\section{Actualización de la información paleoantropológica}

Expongamos ahora la secuencia de los diferentes géneros y especies que participaron en el proceso de hominización y de sapientización, según nos lo presenta Daniel Turbón y James Birx.

Los hominoidea más antiguos son del periodo geológico mioceno 16 a 14 millones de año (crones) eran cuadrúpedos arborícolas y no había braqueadores: Kenyapithecus (en África), Dryopitecus (en Europa) y Sivapitecus (en Asia)

Aunque en África Oriental la Gran falla o fractura geológica del Rift comenzó a formarse hace 20 millones de años en este escenario fundamental con periodos de calma y convulsiones, las que afectaron a la evolución humana debido a sus consecuencias climático-ecológicas, concretamente la formación de dos grandes ecosistemas aislados (el del oeste predominantemente boscoso y la del este predominantemente con praderas y sabanas, fueron la de hace 8 crones (los primeros homínidos) y la de hace 4 crones (los primeros homos). Los homínidos más antiguos, realmente considerados como tales fueron hallados geográficamente entorno al valle del Rift, el Ardipithecus en el etíope y el Orrorin tugenensis en el Gregory. Orrorin data de 6 crones y era bípedo, y Ardhipitecus kadabba (5,5 crones) y Ardipithecus ramidus de 4,4 crones, tenían cierto grado de locomoción bípeda. Orrorin debe ocupar en el árbol filo genético el punto de separación entre la línea de australopithecus y la del Homo.

El género Australopithecus: Cronológicamnte pueden distinguirse dos grupos, el más antiguo entre 4-2 crones y el posterior de 2,5 crones, ambos asociados con cambios climáticos. Este género presenta estatura promedio de 1,20 a 1,50 cms y capacidad craneana promedio de 500 centímetros cúbicos (cc); con amplitud de variación de 390 a560 cc; este género manifiesta ausencia del complejo cortador canino, aunque presenta fosa canina y diastemas caninos, sus extremidades superiores son relativamente más largas respecto a las inferiores en relación a los Homo. Presenta postura erecta y locomoción bípeda, aunque la lateralización de las alas ilíacas que conforman el complejo pélvico no es totalmente completa como en Homo, Sus especies se podrían considerar bípedos arborícolas en transición a bípedos locomotores). Los australopithecus habrían combinado un pie semiarborícola con una capacidad de bipedismo terrestre eficiente. Varios autores asocian las huellas fósiles de pisadas encontradas en 1978 por la famosa paleoantropóloga norteamericana Mary Leakey en Laetoli, Tanzania a los homñinidos australopitecinos.

Éstos se dividen geográficamente en dos: Homínidos de África del Este: Australopithecus anamensis (4,2 a 3,9 crones), Australopithecus afarensis (3,6 a 3 crones). Australopithecus bahrelghazali (3,5 a 3 crones), Kenyanthropus platyops (3,5 crones). Y por otro lado el Homínido de África del Sur: Autralopithecus africanus (3,5-2 crones), no presenta diastema canino y probablemnte se transformó en Homo habilis (Turbón, 2006: 121).

Hace aproximadamente 2,6 crones se formó un casquete polar norte y junto con otros factores sobrevino una desecación climática que se tradujo en África en una retirada definitiva de los bosques en el Rift en tan solo 100 mil años, dejando en la sabana a muchas especies, entre ellas a varios homínidos, haciendo, al mismo tiempo, desaparecer a varios de los taxas anteriores y aparecer otros: concretamente a Homo habilis y al nuevo taxón robusto de Autralopithecus o género Paranthropus (para algunos paleoantropólogos), tanto en África del este como en África del Sur.

El Taxon Robustus presenta las siguientes características (Birx, 1996): Desarrollo de crestas sagital y nucal, 
gran prognatismo en los más antiguos representantes que progresivamente se reduce en los posteriores en función de lo coriáceo de su dieta vegetal (bulbos, raíces, frutos duros), arcos zigomáticos anchos, grandes músculos temporales y maseteros, dentición molarizada y desequilibrada (dientes anteriores pequeños y posteriores trituradores enormes) su cerebro incluye ya áreas de Wernicke y Broca, lo que señala posiblemente rudimentos de lenguaje. Australopithecus (o Paranthropo) aethiopicus (2,7 a 2crones, África oriental), A. boisei (2,4 a 1,2 crones, África del este) y A. robustus (2,4 a 1,2 crones, África del sur). Los dos últimos son contemporáneos a Homo habilis en ambas áreas.

Aparición del género Homo hace aproximadamente 2 crones. LA primera cronoespecie de este taxón es Homo habilis, el cual presenta cambios significativos en su cerebro (encefalización): aumento del tamaño, su reorganización cerebral especialmente de la corteza posterior parietal debido a mayor comunicación lo que implica integración visual, auditiva y sensoriomotora, aumento el riego sanguíneo cerebral a través de las arterias meníngeas (aumentando el número de anastomosis unificadoras entre las ramas de las mismas), presenta estructuras neurológicas adecuadas al habla, ésta desde entonces se volvió indispensable para la sobrevivencia. El paleoantropólogo Ralf L. Holloway (citado por Turbón: 160) señala que se incrementa la integración visual-espacial debido al empleo de instrumentos y a su fabricación (desde hace 2,5 crones de manera intencionada y sistemática), así como al lanzamiento de objetos con fuerza y precisión y a la memoria a largo plazo más sofisticada de posiciones espaciales del yo y de otros, así como memoria de objetos y recursos. Igualmente enfatiza Holloway que se incrementa la cohesión social debido a la fabricación de herramientas, a en la comunicación y a la transmisión de conocimientos

Hasta ahora, sin lugar a dudas, Homo habilis es el primer representante del linaje humano que irá progresivamente adentrándose en un «econicho cultural» a través de las cronoespecies consecutivas $H$. habilis, $H$. erectus y $H$. sapiens, Esta afirmación se hace desde el punto de vista de la sistemática evolutiva (que reconoce otras especies como $\mathrm{H}$. floresiensis y $\mathrm{H}$. nesndhertalensis como expresiones de aislamiento o locales) que se contrapone a la pespectiva filogénetica o cladística evolutiva que reconoce múltiples y variadas especies.

El paleoantropólogo P. V. Tobias reconoce 3 factores en retroalimentación positiva en este proceso de cronoespecies homos: aparición definido del patrón de surcos de la zonas que controlan el lenguaje (visible en los moldes endocraneales), aumento relativo el tamaño cerebral y marcada encefalización y aparición casi sincrónica del uso deliberado y recurrente de herramientas de piedra asociada a la mayoría de los hallazgos paleoantropológicos (Turbón: 146)

Otro proceso nodal para las especies consecutivas de la taxa homo es que en vez de seleccionarse canales de parto cada vez más grandes que hubieran repercutido negativamente en el bipedismo, se dio un retraso en el desarrollo cerebral de la cría de tal manera que el tamaño relativo del cráneo homo al nacer es muy pequeño en relación al que tendrá en la edad adulta. En los póngidos o simios superiores, el neonato tiene al nacer un tamaño de $60 \%$ respecto al tamaño definitivo, en los humanos actuales es de $26 \%$, ello implica que se seleccionó el parto "prematuro"(altricialidad primaria), lo que lleva la respuesta sociocultural (y no etológica como cree Turbón, p. 168) del cuidado grupal del proceso de gestación y parto, transmitiendo eficazmente los conocimientos necesarios para ello y para el cuidado en los primeros meses de vida, debido a la dependencia total del bebé humano antes de caminar por si solo (altricialidad secundaria) Por otro lado, también se seleccionó y hubo respuesta colectiva sociocultural respecto al desafío de la baja demográfica en la fórmula humana de la gestación, el parto asistido (parto rotativo más peligroso y difícil en humanos), la dependencia de la cría y la madurez sexual con el acortamiento de los partos de la hembra y su disponibilidad casi total o continua de la hembra a la sexualidad y la potenciación de la atracción física, igualmente a la incorporación de los machos al cuidado de las crías homos (Lovejoy, en Turbón: 171-172). Por su parte Ernest Mayr plantea la importancia de la poligamia como genética y socialmente más ventajoso que una supuesta "familia nuclear". También ha planteado que un aumento significativo de la cohesión social en los homos, unidos por seguridad, división del trabajo, sexualidad placentera y vínculos gratificantes, actuó sobre sectores importantes del sistema límbico (aumento del septum y de la amígdala lateral) vinculados más al placer que a la agresión y a la ira (amígdala medial límbica).

Se reconoce con $\mathrm{H}$. habilis el inicio de la adaptabilidad a un econicho radiante con ingesta de dieta blanda (alimentos blandos y carroñeo con consumo preferente de médula ósea de animales usando el modo técnico 1). Este homo inicial vivió en zonas limítrofes entre bosque y sabana abierta, practicó la caza ocasional, explotó el econonicho diurno (diferenciándose y evitando a animales competidores de caza que actúan de tarde y de noche) bajo fuerte calor y radiación, generando corporalmente la termorregulación de la temperatura mediante sudoración para impedir la hipertermia cerebral, ello estaría asociado a la pérdida de la pilosidad corporal por lo que su piel debió de ser necesariamente muy pigmentada. (Turbón: 134).

Homo habilis presenta un significativo aumento del volumen cerebral, promediando $640 \mathrm{cc}$, variando de 550 ccc a 775 cc, el promedio es mayor en un 45,1\% al del Australopitheco africanus.. Su bipedismo y postura erguida son mejoradas pues el orificio foramen magnun aparece más adelantado; su mano es más musculosa respeccto a la nuestra, lo que indica cierto grado aún de arboricolismo por lo que probablemente busca refugio en los árboles. Uso de lenguaje hablado, aunque rudimentario, podría haber tenido un repertorio fonético, versatilidad sintáctica y sustancia cognoscitiva.

La especie Homo erectus se desdobla como panafricana y extraafricana, seubica entre 1,9 crones- 0.4 crones 
y es contemporánea con $H$. robustus, e incluso con $H$. habilis.; su capacidad craneana es de 9,50 cc promedio, 30\% más que $H$. habilis, igualmente piernas màs largas que los brazos, canal de parto redondeado, rotación y lateralización mayor de las alas iliacas respecto al género Australopitecus Modo técnico 2 (el enfoque de la cladística reconoce Homo ergaster para África y Homo erectus para Asia (debido a diferencias de sus respectivo occipucios), además de otras variedades locales a las que llama especies Homo como antecessor, heidelbergensis, rodhesiensis, etc.

La Conquista del fuego tiene las evidencias más antiguas de uso en la zona del lago Turkana Koobi Fora en 1,6 crones aunque la producción sistemática se daría hacia 120 ka (Turbón: 189) El uso del fuego presenta las siguientes ventajas socioculturales: defensa contra el frío, modificación del medio, iluminación, uso en la preparación de instrumentos, cocinar, ablandar alimentos, aumentar variedad alimenticia en la ingestión, gracilización de maxilares, molares y músculos de la masticación, mayor atención cerebral (repercutió en reorganización cerebral), esfuerzo comunicativo-lenguaje hablado; el mantenimiento del fuego repercutió en complejidad social, posibilitó el aumento del tiempo libre y incidió en las actividades del arte y la religión.

El primer éxodo de H. erectus (llamado por Turbón «pitecantropización») se dio hacia 1,8 y 1,6 crones desde África hacia Asia: China, Java, Isla Flores (74-12 mil). En las más recientes expansiones territoriales de las especies se da la coexistencia de erectus y sapiens a partir de 80 hasta $50 \mathrm{Ka}$, por tanto se consideran especies simpátridas.

La Transición de erectus a sapiens se presenta hacia 0.4 crones (400 mil años o 400Ka). Varios autores reconocen varios Homo sapiens: arcaico, tardío y final, desde 600 ka, 300-120 ka y 120-a 50 ka respectivamente

La especie reconocida como Homo sapiens neanderthalensis presenta capacidad craneal de 1200 a 1700 cc., con promedio de 1520 cc., espacio retromolar por estrechamiento de la rama mandibular y la posición de los músculos masticatorios y la raíz del hueso malar zigomático. Cuerpo robusto y muy musculoso, los huesos de la piernas más gruesas que los nuestros y sus articulaciones también más grandes, su peso cerca de $30 \%$ más que los humanos actuales, extremidades cortas respecto al tronco, baja estatura, adaptación al frío y gran actividad física. Se conocen en sus restos fósiles variaciones en Medio Oriente y en Europa.

La divergencia entre el linaje mitocondrial genético humano actual y el neandertal es de circa 690 y 550 mil años, a nivel de poblaciones de 300 a 250 mil. No se excluye -por análisis de mtDNA- totalmente la posibilidad de que ciertos miembros de las 2 especies se mezclaran en el pasado (Turbón: 248), sin embargo, los humanos actuales presentan homogeneidad genética, lo que apunta a un origen común a partir de un grupo pequeño (quizá unos $10,000)$ de individuos provenientes de África hace unos 200 mil años dispersándose hace 100 mil y llegando a Europa hace 45000 .

Los neandertales en sus patrones socioculturales: cuidaban a sus heridos, hacían enterramientos funerarios (tumbas con restos de herbívoros, útiles líticos y vegetales como flores) ligados a algún tipo de creencia y sentimientos religiosos como "culto al oso" (por evidencia de cráneos orientados hacia la entrada de una cueva), uso de ornamentos personales, pigmentos naturales, objetos de intercambio (entre ellos y quizá con sapiens sapiens). Sus herramientas pertenecen al tecnocomplejo musteriense, chatelperroniense (Francia) y uzzeliense (Italia). Su extinción-desaparición va de 43 a 36 mil; planteándose las siguientes hipótesis al respecto: por competición económica de los recursos, por absorción de nuevas poblaciones con mayor potencial demográfico, conflictos directos y eliminación física con sapiens sapiens. Se ha señalado una superioridad neurológica y mayor variedad de comportamientos simbólicos de este último. O también debido a una mayor expansión demográfica del doble sapiens (a partir de 40 000 años, una vez salidos de África pasando por próximo oriente sustituyendo o reemplazando a poblaciones homos diferentes en Asia, África y Europa).

De esta nuestra especie se dieron expansiones de poblaciones africanas desde el nordeste por el Nilo y el cuerno de África entre 130 a $60 \mathrm{Ka}$, vinculadas a periodo de humedad y que luego migraron en periodo de aridez a zonas más favorables. Así pues, sapiens sapiens va a presentar una mayor densidad de población, adopción de una nueva tecnología (modo técnico 4) y una esperanza de vida mayor y por tanto mayor acumulación de experiencias en el grupo y potenciales mayores mejoras culturales. La cultura auriñaciencie (basada en el Modo 4) llega a Europa en torno a $40 \mathrm{Ka}$. La ocupación de los sapiens sapiens es mediante oleadas de migraciones y expansiones por diversas rutas llegando a China 67 ka, Australia 60, Indonesia 55 ka América 40. Pero nuestra sociedad sapiencial estaría ya prefigurada hace unos $12 \mathrm{ka}$, coinicidiendo con el reloj mitocondrial para el origen de la diversidad genética actual y el interglacial cálido Riss-Wurm.

El Homo sapiens sapiens, desde el punto de vista de la taxonomía zoológica quedaría ubicado según el siguiente Cuadro:

Taxonomía Filogenética del Homo Sapiens Sapiens

\begin{tabular}{|l|l|l|}
\hline \multicolumn{1}{|c|}{ CATEGORÍA } & \multicolumn{1}{c|}{ TAXÓN } & \multicolumn{1}{c|}{ DESCRIPCIÓN } \\
\hline $\begin{array}{l}\text { Dominio o } \\
\text { Superreino }\end{array}$ & $\begin{array}{l}\text { Eucariotes } \\
\text { (Eucarya) }\end{array}$ & $\begin{array}{l}\text { Células que presentan núcleos y organelos celulares membranosos } \\
\text { diferenciados. }\end{array}$ \\
\hline
\end{tabular}




\begin{tabular}{|c|c|c|}
\hline Reino & $\begin{array}{l}\text { Animales } \\
\text { (Animalia) }\end{array}$ & $\begin{array}{l}\text { Todos los seres vivos con células eucariotas y que no hacen la foto- } \\
\text { síntesis. }\end{array}$ \\
\hline Clado & Metazoos & Todos los animales pluricelulares. \\
\hline $\begin{array}{l}\text { Filo o } \\
\text { Filum }\end{array}$ & $\begin{array}{l}\text { Cordados } \\
\text { (Chordata) }\end{array}$ & $\begin{array}{l}\text { Todos los animales que tienen notocordio (estructura de fibras nervio- } \\
\text { sas que recorren longitudinalmente el cuerpo) }\end{array}$ \\
\hline $\begin{array}{l}\text { Subfilo o } \\
\text { Subfilum }\end{array}$ & $\begin{array}{l}\text { Vertebrados } \\
\text { (Vertebrata) }\end{array}$ & $\begin{array}{l}\text { Todos los animales Cordados que tienen el notocordio protegido (re- } \\
\text { cubierto) por una placa ósea. }\end{array}$ \\
\hline Superclase & $\begin{array}{l}\text { Tetrápodos } \\
\text { (Tetrapoda) }\end{array}$ & Todos los animales Cordados Vertebrados con cuatro extremidades \\
\hline Clase & $\begin{array}{l}\text { Mamíferos } \\
\text { (Mamalia) }\end{array}$ & $\begin{array}{l}\text { Todos los animales Cordados Vertebrados Tetrápodos que tienen } \\
\text { pelo en la piel y glándulas mamarias para alimentar a sus crías. }\end{array}$ \\
\hline Subclase & $\begin{array}{l}\text { Terios } \\
\text { (Theria) }\end{array}$ & $\begin{array}{l}\text { Todos los animales Cordados Vertebrados Tetrápodos Mamíferos que } \\
\text { conciben crías fetales (actualmente, todos menos el Ornitorrinco y el } \\
\text { Equidna) }\end{array}$ \\
\hline Infraclase & $\begin{array}{l}\text { Euterios } \\
\text { (Euteheria) }\end{array}$ & $\begin{array}{l}\text { Todos los animales Cordados Vertebrados Tetrápodos Mamíferos } \\
\text { Terios que alimentan al feto en el útero materno (todos menos los } \\
\text { marsupiales) }\end{array}$ \\
\hline Orden & $\begin{array}{l}\text { Primates } \\
\text { (Primata) }\end{array}$ & $\begin{array}{l}\text { Algunas características: Uñas planas, } 5 \text { dedos, pulgar oponible, pren- } \\
\text { silidad, visión estereoscópica. }\end{array}$ \\
\hline Suborden & $\begin{array}{l}\text { Antropoides } \\
\text { (Anthropoidea) }\end{array}$ & $\begin{array}{l}\text { Todos los monos (con cola), los simios (sin cola) y todas las especies } \\
\text { de homos. }\end{array}$ \\
\hline Infraorden & Catarrinos & Septo nasal estrecho y orificios nasales dirigidos hacia adelante \\
\hline Superfamilia & $\begin{array}{l}\text { Hominoides } \\
\text { (Hominoidea) }\end{array}$ & $\begin{array}{l}\text { Todos los simios (sin cola) y los homos. Tienen u periodo de gestación } \\
\text { mayor, }\end{array}$ \\
\hline Familia & $\begin{array}{l}\text { Homínidos } \\
\text { (Hominidae) }\end{array}$ & $\begin{array}{l}\text { Australopithecus, Ramapithecus, Paranthropus, Homos (casi todos } \\
\text { fósiles). Capacidad craneana arriba de los } 400 \mathrm{C} 3 \text {, caninos pocos so- } \\
\text { bresalientes. }\end{array}$ \\
\hline Género & Homo & $\begin{array}{l}\text { Todos los homos fósiles (hábilis, erectus, ergaster, rudolfensis, an- } \\
\text { tecessor, sapiens, etc.) y el homo actual. Aparecen desde hace } 2.4 \\
\text { crones, elevado desarrollo neuromotriz, capacidad craneal va de } 642 \\
\text { a } 1600 \text { cc. }\end{array}$ \\
\hline Especie & Homo Sapiens & $\begin{array}{l}\text { Formas antiguas y actuales de Sapiens (neanderthalensis, arcaicos } 1 \\
\text { y } 2 \text {, sapiens sapiens). Dedo gordo del pie paralelo a los demás. Crías } \\
\text { nacen prematuras por lo que requieren cuidados colectivos. Cerebro } \\
\text { más grande, redondeado y complejo. Capacidad craneal llega a ser } \\
\text { en neandertal } 1700 \mathrm{cc} \text {. }\end{array}$ \\
\hline $\begin{array}{l}\text { Subespecie } \\
\text { (Según algunos } \\
\text { autores) }\end{array}$ & $\begin{array}{l}\text { Homo Sapiens Sa- } \\
\text { piens }\end{array}$ & $\begin{array}{l}\text { Todos los hombres "modernos" desde hace unos } 50,000 \text { años o un } \\
\text { poco más. Lenguaje simbólico más avanzado. Desarrollo tecnocultu- } \\
\text { ral y civilizatorio. Único representante homínido y homo vivo. Expan- } \\
\text { sión totalmente planetaria y proto-cósmica. }\end{array}$ \\
\hline
\end{tabular}

\section{HERRAMIENTAS, PROCESO DE TRABAJO E INDUSTRIAS LÍTICAS HOMOS}

Aunque el primatólogo Sabater Pi (1992), y otros etólogos, ha demostrado que los llamados póngidos (género que según los seguidores de la teoría sintética evolutiva abarca orangutanes/pongo, chimpancés/pan y gorilas/gorilla) especialmente los chimpancés, usan y elaboran instrumentos o utensilios para incidir sobre el medio ambiente para (fundamentalmente) procurarse alimentos y defenderse a la manera de un proto-trabajo dentro de una proto-cultura; y a partir de ello incluye dicha habilidad como parte de un «modelo hominoideo» de siete facies (características comunes). Consideramos que la fabricación de «herramientas» propiamente dichas se da con los homos, pues los pre-australopitécidos y los australopitécidos podrín equipararse más a las habilidades instrumentales póngidas (ubicados ambos como simios según su reconocida denominación fósil) que a las homos. Los paleoantropólogos Eldredge y Tattersall (1986) definen claramente que para considerarse herramienta un utensilio elaborado tiene que formar parte de un pool o kit de ellas, es decir, que haya variaciones de ellas a partir de una técnica productiva fundamental (técnica directriz que da sentido al conjunto, Martínez, 2019:87). Así, dichas variaciones juegan el papel de brindar posibilidades diversas para la práctica de tareas similares y complementarias: de una técnica se explora y se obtiene siempre -dicen Eldredge y Tattersall- todas las potencialidades que encierra este tipo de herramientas. Podríamos decir que dichas tareas que se resuelven con el kit son semejantes y también se van complementando (formando una totalidad). $\mathrm{O}$, mejor, tareas comunes y compartidas porque están ancladas en una serie de operaciones laborales que son necesarias para la sobrevivencia colectiva: caza, corte, raspado, curtido, desgarre, limpieza, segada, pulido, etcétera; acciones que dichos instrumentos de trabajo como herramientas tienen que realizar sobre diferentes objetos de trabajo: la carne, la piel, los huesos, la tierra, los tallos, las semillas, los tubérculos, etc. Por ello es que se han bautizado como «modos» técnicos o primigenias «industrias» de trabajo productivo. 
Las llamadas industrias líticas o modos técnicos del paleolítico abarcan con sus cambios, avances y experimentaciones materiales alrededor del 99\% de la técnica-tecnología de los homos.

Se ha discutido mucho el origen propiamente homo de las verdaderas herramientas. Y se tiene una clasificación de ellas a través de los llamados y enumerados «modos», que sintetizaremos en lo que resta de este texto. El homo habilis es el que ha sido más señalado y consensuado para ser el primero (de allí su nombre: humano habilidoso) en construir ese equipo o pool de herramientas, esto es, el que inauguró la industria lítica y el despegue histórico del proceso de desarrollo de la técnica-tecnología humana que ha llegado a través de múltiples revolucionamientos a la plataforma cibernética de las tecnociencias del capitalismo imperialista del siglo XXI.

Otro aspecto importante que tiene que ver con la discusión de F. Engels y K. Marx respecto al papel del proceso de trabajo en la conformación de la humanidad y la humanización, esto es si estas herramientas primordiales, por un lado, contienen y condensan las capacidades humanas técnicas, mentales, simbólicas y estéticas; y por el otro, evidencian las transformaciones habidas en la constitución corporal-cerebral, genética, ecológica y social. La conformación de lo que Edgar Morin llama paradigma homo y que significaría ni más ni menos la constitución orgánico-societal y metabólica de los ejes centrales que posibilitaron la formación humana. Desde nuestro punto de vista estos «modos» o todos instrumentales confirman ambas dimensiones: las capacidades homos y sus transformaciones en su mutua interacción o sea en su dialéctica. Por ello es tan importante y nodal para el materialismo histórico la totalidad conceptual de proceso de trabajo y praxis, ya que en ella se encierra la semilla y el telos humanos (no predeterminados, por ejemplo, a las maneras deificadas o evolucionistas, sino abiertos) para entender, explicar y seguir generando las transformaciones y realizaciones (afirmaciones) humanas en la relación sujeto humano-objeto práctico de la historia pasada, presente y futura de la especie humana genérica.

Así pues, toda herramienta con el sello humano (y más aún si se trata del kit integrado de ellas) desde la primera de ellas hasta las mega computadoras cibernétic-cuánticas más sofisticadas del cibercapitalismo contienen y despliegan esas expresiones práctico-mentales y sus transformaciones (aunque en el capitalismo han quedado cada vez más subsumidas a su lógica alienadora). Así -creemos- quedan inoperantes y rebasadas las discusiones si el trabajo humano (principalmente el no cosificado) es meramente material o técnico o se le puede agregar lo simbólico y/o lo estético, pues esa concepciones no conocen y no reconocen la integración de esas dimensiones en el proceso de trabajo y por ende en las praxis.

Según Juan Luis Arsuaga e Ignacio Martínez en La especie elegida, la siguiente sería la secuencia de los Modos técnicos (tecnológicos) o Industrias líticas principales en el proceso de hominización-sapientización. Veamos:

Modo 1: Industria Lítica Olduvayense (Los primeros Homo: 2,5 millones de años; Paleolítico Inferior): Asociada a Homo habilis. Dicha Industria Consiste en cantos y rocas tallados sin una forma estandarizada. Entre estos se encuentran los llamados choppers (trabajados de una sola cara), los chooping tools (tallados de las dos caras), y las lascas sin retocar. El proceso de fabricación de estos instrumentos requiere secuencias de pocos golpes. También utilizan cantos y rocas sin modificar, a modo de martillos y yunques. La necesidad de obtener bordes afilados para cortar es posible que surgiera cuando los primeros humanos empezaron a consumir carne y precisaron de filos tanto para abrir la gruesa piel de grandes animales como para cortar tendones y trocear músculos; también utilizarían los cantos para fracturar los huesos y extraer el tuétano. También, sin duda, utilizaban los filos de los instrumentos de los instrumentos de piedra para cortar plantas y hay quien piensa que la preparación de productos vegetales duros, los primeros Homo la llevaban a cabo con útiles de piedra. Su yacimiento principal es el de Olduvai (Tanzania).

Modo 2: Industria Lítica Achelense (Homo erectus/ergaster: 1,6 millones de años; Paleolítico Medio): Incluye núcleos o grandes lascas con talla por las dos caras llamados bifaces, como las hachas de mano, los hendedores y los picos; estos instrumentos muestran una gran estandarización en su confección y requieren una larga secuencia de gestos, incluyendo el giro del núcleo en la mano mientras va siendo golpeado por el percutor para extraer las lascas. El resultado es un instrumento en el que todo o casi todo su borde es filo. Las hachas de mano son bifaces simétricos con filos laterales que convergen hacia un extremo apuntado, y los hendedores son bifaces simétricos que en un extremo presentan un filo recto. Las hachas de mano probablemente eran utilizadas como instrumentos de múltiple uso, para cortar la carne, trabajar la madera y quizás también para preparar pieles. La industria Achelense más antigua que se conoce tiene cerca de 1,6 m.a. y procede del yacimiento tanzano de Olduvai.

Modo 3: Industria Lítica Musteriense (Homo neandertal: 300,000). Se desarrolla en el Paleolítico Medio y se prolonga hasta el superior. Este modo técnico, se caracteriza porque mediante la talla se preparan los núcleos dándoles una forma determinada (similar al caparazón de una tortuga), para luego extraer a partir de ellos las lascas, que más tarde será retocadas para proporcionarles el acabado final. Esta cadena operativa se conoce como técnica Lavallois y de cada núcleo se obtienen varios instrumentos, aprovechando de este modo mejor la materia prima y el esfuerzo. Además, esta claro que supone una notable capacidad de abstracción, porque no se trabaja la piedra para producir directamente el instrumento, sino que se añade un paso intermedio (el núcleo Lavallois). El Musteriense se extendió por Europa, Oriente Próximo u norte de África, es decir, en un área circunmediterránea, mientras que otras industrias del Modo 3, o Paleolítico Medio se encuentran en el resto de África (donde son agrupadas bajo el término de «Middle Stone Age»). Los orígenes del Modo 3 se sitúan entre hace 300,000 y 200,000 años según regiones, al parecer primero en el África subsahariana y luego en Europa. 
Modo 4: Industrias Líticas Auriñacienses (Homo Sapiens: 42,000 años). La primera industria del Paleolítico Superior. Técnicamente el modo 4 se caracteriza por la preparación de núcleos alargados para la obtención de lascas finas y de bordes paralelos, y al menos dos veces más largas que anchas. Estas hojas eran luego retocadas y transformadas en una gran variedad de útiles, entre los que destacan los buriles (instrumentos biselados que se usaban para trabajar el hueso, la asta o el marfil) y los raspadores distales (hojas con un extremo retocado que se utilizaban para preparar pieles). Esta técnica permite el máximo aprovechamiento de la materia prima, obteniendo de cada piedra más longitud de filos (sumados los de todos los útiles producidos a partir de ella) que con ningún otro método. El Modo 4 también se diferencia por la utilización del hueso de marfil y la asta como materias primas para la confección de instrumentos y elementos de adorno personal. Asociadas (algunos miles de años después de su aparición) a las industrias del Modo 4 aparecerá también el arte en forma de figuras transportables de animales y personas, y de pinturas y grabados rupestres. El Auriñaciense se extiende por Europa en poco tiempo, hace unos 40,000 años o poco más.

En algunos yacimientos de la cornisa cantábrica y del oeste y centro de Francia hay, intercalados entre los últimos niveles Musterienses y los primeros Auriñaciences, niveles intermedios con una industria que tiene características comunes a ambos modos técnicos (3 y 4). Esta industria se llama Chatelperroniense (asociada generalmente a Homo sapiens: 35,000 años Paleolítico superior y medio); un equivalente en Europa central podría ser el Szeletiense, y en Italia el Uluzziense. El Chatelperroniense es una evolución del Musteriense que incorpora elementos del Modo 4 como hojas alargadas y utensilios de hueso y marfil.

\section{CONCLUSIÓN}

El proceso de trabajo como lo concibieron Karl Marx y Friedrich Engels desde la dialéctica material del metabolismo entre el ser humano y la naturaleza, tal como lo planteamos en la primera parte de este ensayo, es el corazón tanto del proceso de hominización, como del proceso de sapientización y también del proceso de humanización hacia su plenitud. En cada uno de dichos procesos tiene importancia diferenciada el diseño, la elaboración y perfeccionamiento (e incluso distorsión dentro del capitalismo) de las herramientas y medios de trabajo. Asimismo, los procesos de trabajo conllevan tareas y funciones diferentes, mientras que en los primeros se constituyen como fundamentadores de la sobrevivencia y consolidación de la técnica, en el tercero se constituye potencialmente como proceso de trabajo liberador al codificarse materialmente en la automatización del trabajo y en la liberación de tiempo libre (disposable) para el disfrute del trabajador social y del conjunto de la sociedad. Engels en el texto que hemos comentando aquí, sigue estos lineamientos para detenerse en los dos primeros y esbozar el tercero siguiendo los planteos que Marx y él mismo habían seguido en sus trabajos temáticos al respecto.

El papel del trabajo en la hominización-sapientización conlleva una secuencia lógico histórica dialéctica y sus componentes forman una totalidad que ha sido Engels el que la ha sabido delinear originalmente. Y este delineamiento no ha sido una mera intuición brillante (como cree Raymundo Martínez), sino una demostración de destreza argumentativa de un investigador crítico de la historia humana y un militante socialista que a pesar de la carencia de informaciones y datos paleantropológicos, climatológicos, etc., abundantes en su época, pudo sostener su argumentación materialista basado en el metabolismo ecológico progresivo de la dialéctica sociocultural del proceso de trabajo. Dichos componentes decisivos como hemos pasado revista aquí, implicaron el bipedismo, (postura y andar, cambios anatómicos, fisiológicos, etológicos, etc.), visión y nueva perspectiva de otear los espacios, cambios en la anatomía y en destrezas operativas de la mano, expansión y reorganización del cerebro y de los sentidos y capacidades vinculados a las áreas cerebrales y con ello, en general, reestructuraciones de todo el cuerpo, importancia de la ingesta de la carne y su cocimiento, así, como la dieta omnívora, el lenguaje articulado y las capacidades de comunicación, cooperación y enseñanza-aprendizaje, y en fin, la elaboración del universo socio cultural y su expansión socio-político-histórica.

Ha habido otros autores después que él que se han valido de su propuesta para modificarla y a veces distorsionarla proponiendo otros "modelos" que en el libro del antropólogo Erick Klamroth son expuestos y criticados por insuficientes, parciales y faltos precisamente del papel y el significado material metabólico que ha tenido el proceso de trabajo en la conformación histórica de las sociedades humanas, en sus relaciones sociales, fuerzas productivas, modos de vida y de producción-reproducción, así como en las formaciones socioculturales y en las civilizaciones humanas. Esta carencia es sintomática de su incapacidad para entender la dialéctica de la historia humana: sus dificultades y potencialidades; por tanto, la reivindicación científico-crítica del papel del trabajo en la historia global de la humanidad, desde la hominización a la humanización sigue teniendo más que nunca en estos tiempos de crisis multidimensionales (incluyendo la económico-ecológica y la civilizacional), una vigencia inigualable.

Thomas C. Patterson (2014) ha concluido precisamente que las líneas generales de la teoría de Engels (y de Marx) sobre el papel del proceso de trabajo en la autocreación de las paleo-sociedades humanas (Morin, dixit) han resistido la prueba del tiempo, aunque el tipo y la cantidad de información detallada disponible hoy en día sea infinitamente más rica que cuando Engels escribió su célebre el ensayo. Esto es en buena parte lo que hemos querido demostrar en esta segunda parte de nuestro ensayo dedicado al bicentenario del nacimiento del maestro de Barmen. 


\section{REFERENCIAS BIBLIOGRÁFICAS}

Arsuaga, José Luis \& Martínez, Ignacio. (2004). Ediciones Tema de hoy, Madrid, España.

Birx, James. (1996), "Fossil hominid and our own species", en Evolución: aspectos interdisciplinares, Universidad de Zaragoza, España, pp. 227-242.

Cordón, Faustino. (1982) Cocinar hizo al hombre, Tusquets, Barcelona (4ta reimpresión).

Darwin, Charles. (1985) El origen del hombre y la selección en relación al sexo. Diana, México, 15ava reimpresión.

Eldredge, Niles \& Tattersall, Jan. (1986). Los mitos de la evolución humana, Fondo de Cultura Económica, México, D. F.

Engels, Friedrich. (1970). El papel del trabajo en la transformación del mono en hombre, Progreso, Moscú.

Klamroth, Erick. (1987). El papel del trabajo en el proceso de hominización, Instituto Nacional de Antropología e Historia, Colecc. Cientifica 166. México, D. F.

Martínez Fernández, Raymundo. (2019). "El concepto de proceso de trabajo en Karl Marx y el proceso de hominización", en Contrahistorias, Núm 31, pp. 73-97

Marx, Karl. (1978). Elementos fundamentales para la crítica de la economía política. Tomo 2, siglo XXI, México, D. F:

Marx, Karl. (1978). El Capital, crítica de la economía política, Tomo I, Vol 1. Siglo XXI, México, D. F.

Morin, Edgar. (1984). El paradigma perdido. Ensayo de bioantropología. Kairós, Barcelona.

Petterson, Thomas. (2014). Karl Marx, antropólogo. Ediciones Bellaterra, Barcelona.

Sabater Pi, Jordi. (1992). El chimpancé y los orígenes de la cultura, Editorial Anthropos, 3era edición, Barcelona.

Turbón, Daniel. (2006). La evolución humana, Ariel Barcelona, España.

How to cite this article: Adame Cerón, M. Ángel. (2020). El papel del trabajo en la hominizacion y humanización. Religación. Revista De Ciencias Sociales Y Humanidades, 5(23), 63-77. Recuperado a partir de http://revista.religacion.com/index. php/religacion/article/view/597

Submitted: 10 January 2020 Accepted: 18 March 2020 Published: 31 March 2020

Religación. Revistais de Ciencias Sociales y Humanidades is a peer-reviewed open access journal published by CICSH-AL Centro de Investigaciones en Ciencias Sociales y Humanidades desde América Latina |Religación| 